ISSN 2305-2678 (Print); ISSN 2305-5944 (Online)

DOI: http://dx.doi.org/10.4314/rj.v28i1.8

\title{
Biotechnology for Improving Food Security in Rwanda
}

\author{
Daphrose Gahakwa, Theodore Asiimwe, Ntizo Senkensha, Jöelle Kajuga, Placide \\ Rukundo, Esperance Munganyinka and Jane Kahia \\ Rwanda Agricultural Research Institute (ISAR), P.O. Box 138, Huye, Rwanda;
}

\begin{abstract}
$\underline{\text { Abstract }}$
About 200 Million people in the world suffer from hunger. The United Nations (2007) estimates that the world population will reach 8.1 Billion people by 2030. Meeting global food requirements will necessitate increasing food production by $50 \%$. The most attractive strategy to meet this challenge is to increase smallholder agricultural productivity. This strategy will not only increase food supply, it will also increase smallholder incomes, reduce malnutrition and improve livelihoods of the poor. Biotechnology has the potential to increase the world's food output and reduce food insecurity. Plant biotechnology offers a wide scope of possibilities for increasing productivity, diversification and development of a more sustainable agriculture. This technology includes biopesticide production, plant tissue culture techniques, and the use of advanced molecular biology techniques for plant transformation, genomic analysis coupled with breeding and plant disease diagnoses. Agricultural biotechnology will contribute to food security through technologies that improve yield and quality and can easily be adopted by small scale farmers. The technology should, therefore, be simple, low cost and have little risk to humans and the environment. Tissue culture offers such kind of technology. This communication discusses the status of tissue culture research In Rwanda and how modern biotechnology has led to increased productivity and food security in some developing countries.
\end{abstract}

Key words: Biotechnology, Food security, Tissue Culture

\section{Introduction}

The world food situation is very insecure as demographic growth is steadily increasing the competition for food, energy and water. Good land resources are in short supply as fertile farm land is being lost due to erosion, water logging, salinity and urban development. Furthermore, sudden weather changes have aggravated the situation with negative impacts on food production and supply. 
On the other hand, the conventional agricultural research does not keep pace with the steady growth needed in the sector to balance demand and supply of products. Biotechnology provides powerful tools for improvement of agricultural productivity and quality by accelerating research for development when the classical approaches alone are inadequate or take too long to achieve results (Ahloowalia et al.,2002).

Tissue culture (TC) or in vitro propagation is the cultivation of plant cells, tissues, or organs on specially formulated nutrient media (Ahloowalia, et al., 2004). Under the right conditions, an entire plant can be regenerated from a single cell. Plant tissue culture is a technique that has been around for more than 30 years and it is an important technology for developing countries for the production of disease-free, high quality planting material and the rapid production of many uniform plants (Kahia, 1999). Tissue culture can be used to increase the amount of planting material to facilitate distribution and large scale planting. In this way, large number of plants can be produced in a short time. Tissue cultured plants are known to establish more quickly, grow more vigorously and have a shorter and more uniform production cycle, and produce higher yields than conventionally propagated plants (Bertrand et al., 2005).

In vitro propagation is based on enhanced axillary bud proliferation and the ability of differentiated often mature plant cells, to dedifferentiate and develop new meristematic centers that are capable of regenerating fully normal plants (Ziv, 1999). Regeneration is normally through two morphogenic pathways; organogenesis- the formation of unipolar organs and somatic embryogenesisthe production of bipolar structures. Somatic embryos have a shoot and root meristem. All plant somatic cells, once isolated and cultured in vitro, are capable of expressing totipotency. The injured cells in the outer layers of the isolated explants evolve ethylene that induces the inner cells to undergo differentiation.

After the loss of coordinated control which is ensured by cell division, the formation of new gradients of endogenous phytohormones in the dedifferentiated cells enhance cell division in response to the growth regulators added to the media (Barciszewski, et al., 2007).

Plant regeneration in vitro is dependent on the manipulations of the organic and inorganic constituents in the media as well as the type of explants and the plant species. In most plants, successful regeneration from callus or directly from explants takes place after a series of subculture in various media in a sequence 
which is often specific to the species, variety, or the newly introduced genotype (Mineo, 1990). The determining factors are the combination of the concentrations in relation to media volume and the composition of growth promoting regulators in the medium, the physiological status and competence of cells and their capability for the morphogenic expression (Christianson, 1987).

Plant tissue culture is a straightforward technique and many developing countries have already mastered it. Its application only requires a sterile workplace, nursery, and green house, and trained manpower. Unfortunately, tissue culture is labor intensive, time consuming, and can be costly. Plants important to developing countries that have been grown in tissue culture are oil palm, plantain, pine, banana, date, eggplant, jojoba, pineapple, rubber tree, cassava, yam, sweet potato, and tomato among others (Hartmann, 1997). This application is the most commonly applied form of traditional biotechnology in Africa and Asia.

\section{Tissue Culture in Rwanda}

Rwanda's economic policies since independence are said to have targeted agriculture as the main engine of economic growth. However, the agricultural sector has continued to perform poorly, with consistently declining productivity. The reduction in production has been attributed to many factors; key among them are diseases, pests and lack of disease resistant varieties. This is further aggravated by the increasingly degraded environment and the unparalleled changes in global climate. The Rwandan government has in the recent past overhauled agricultural policies by encouraging crop intensification and production of high value crops and modern livestock management as a way of increasing productivity. In fact, the government envisages replacing subsistence farming by a fully commercial agricultural sector by 2020 (MINAGRI, 2004).

Biotechnology especially Tissue Culture provides powerful tools for improvement of agricultural productivity hence increasing food security. Currently, the Rwanda Agricultural Research institute is conduction research in plant Biotechnology, where emphasis is put on tissue culture, plant and animal diseases diagnosis's and use of microbial biotechnology for development of biofertilizers. Tissue culture methods permit the production of relatively 
uniform plants on a large scale production of disease free planting materials in a shorter period than under conventional methods.

\section{Banana Tissue culture}

The bananas commonly available are cultivars of Musa acuminata. They are one of the most important fruits in the world, both as a staple food as well as a major export commodity for many tropical and sub-tropical countries Banana has been grown in Rwanda for many centuries; however, production has taken a downward trend in the last couple of years. The reduction in production has been attributed to many factors; key among them are diseases, pests and lack of disease resistant varieties and clean planting materials. Farmers traditionally use suckers as planting materials. Each mother plant produces only one to eight suckers per planting season which is grossly inadequate. The solution is an efficient propagation of cheap and clean planting materials through tissue culture. Micropropagation protocol for banana developed at ISAR in Rwanda using shoot tips on a defined nutrient media containing specific plant growth regulators. The steps include sterilization and establishment of shoot tip cultures (Figure 1 a), induction of multiple shoots in a Murashige and Skoog media supplemented with a cytokinin (Figure 1b), elongation, rooting of shoots (Figure 1c) and hardening of rooted plantlets in the green house (Figure 1d). The technique can be useful for rapid multiplication of banana cultivars. One of the main advantages is the production of disease free uniform age and size planting material which can be made available throughout the year.

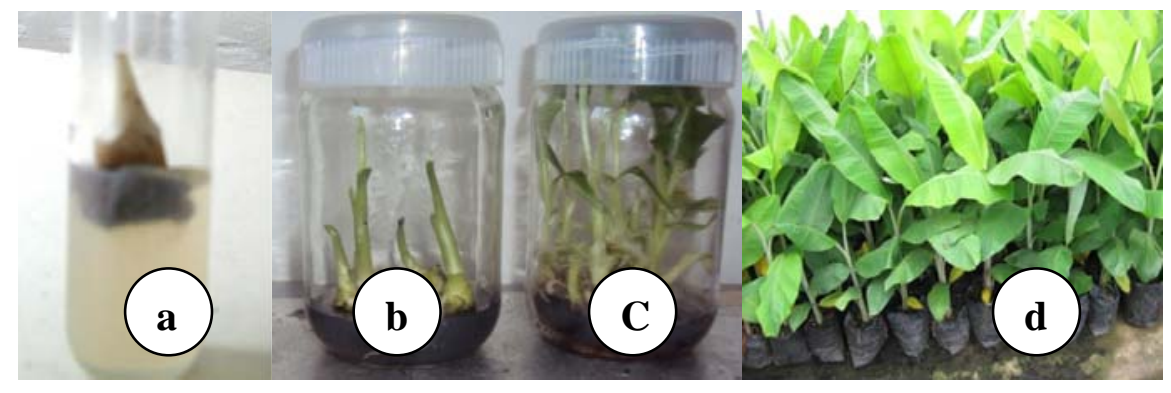

Figure 1: In vitro propagation of banana 


\section{Pineapple Tissue culture}

The pineapple (Ananas comosus) is the most famous and economically important member of the Pineapple family (It is the only bromeliad with edible fruit). The family is almost exclusively from the New World, with over 2000 species besides the pineapple native to the tropical Americas. The pineapple, however, can now be found in all tropical regions. In Rwanda There is increasing interest in pineapple cultivation in the country and proliferation of post-harvest processing businesses supported by the Government's determination to promote horticulture and agricultural diversification. However, pineapple farming expansion is hampered mainly by limited availability of planting materials. Pineapple is traditional propagated by suckers and slips. The number of seedlings obtained using these methods are few and cannot supply the farmers demand for large quantities of planting materials. Tissue culture offers a feasible solution to production of large number of plants. An efficient and cost-effective method for commercial micro propagation of Smooth Cayenne pineapple has been developed. Explants derived from crown tip meristems are isolated, sterilized and cultured on MS medium supplemented with Benzylaminopurine (Figure 2a). Multiple shoots are regenerated via direct organogenesis (Figure $2 b$ ) and rooting achieved by culturing the shoots in a media supplemented with an auxin (Figure $2 \mathrm{c}$ ). The rooted shoots are removed from media and weaning in a sterilized soil substrate (Figure 2d).

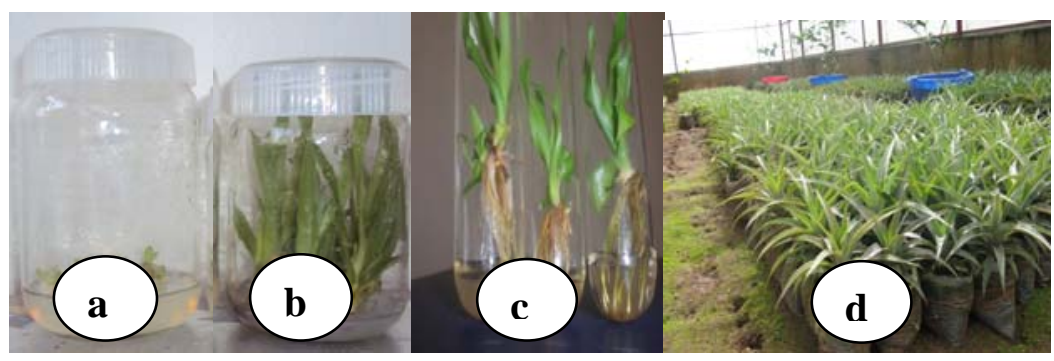

Figure 2: In vitro propagation of pineapple

\section{Tissue Culture of Coffee}

Coffee (Coffea Arabica) is an important cash crop in Rwanda earning the country foreign currency. However, from the year 2000 its importance has diminished due to a number of factors key among them reduced productivity, 
low quality and low international prices. Moreover most of the trees are old and are attacked by diseases and pests. Conventionally, coffee is propagated from seed or by vegetative cuttings. Seed propagation is associated with inherent uncontrolled genetic variation in heterozygous cultivars, slow rates of multiplication of seed and short span of seed viability. Propagation of coffee by vegetative cuttings guarantees uniformity but cuttings generate relatively low multiplication rates as they can only be obtained from orthotropic branches (Kahia, 1999). Multiplication by Tissue Culture could provide a viable alternative to these traditional methods. At ISAR, the protocol described by Kahia, 1999 had been adopted. Leaf explants are sterilized and then cultured on Murashige and Skoog medium supplemented with benzylaminopurine and incubated in the dark at $25^{\circ} \mathrm{C}$ (Figure 3a). Somatic embryos are regenerated form the cut-edges of the leaf explants (Figure $3 b$ ) and germinated in a media supplemented with an auxin (Figure 3c). The plantlets are transferred to a soil, sand, manure potting mixture and then weaned in a greenhouse (Figure $3 \mathrm{~d}$ ).

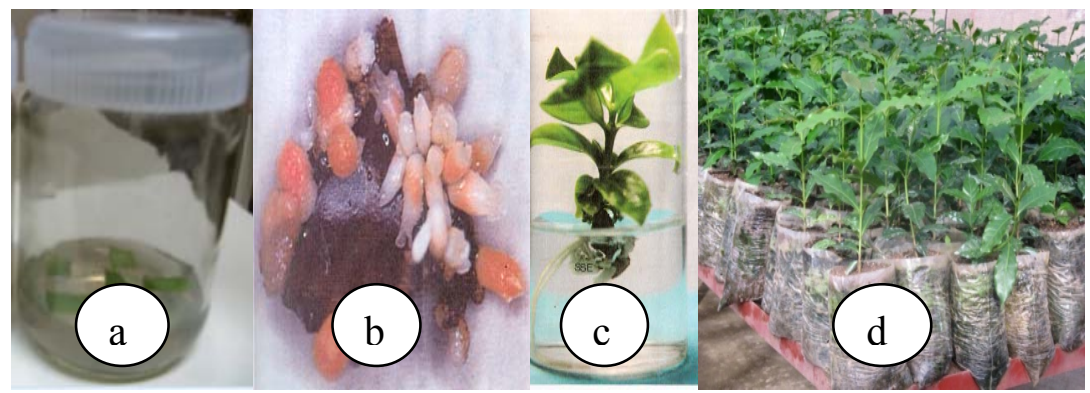

Tissue culture of passion fruit Figure 3: In vitro propagation of coffee

Passion fruit (Passiflorae edulis Sims) is one of most economic crops cultivated in Rwanda particularly in Southern Province. Its fruit is edible and medicinal. The fruit juice is a good source of vitamin $\mathrm{C}$ carotenoids (vit A), $\beta$ carotene, potassium and dietary fibre and due to its aroma, flavour and high sugar content; it is used as a dessert fruit. The plant is traditionally propagated by seeds and cuttings. These methods have limitation due to the short viability of seeds and on the other hand, vegetative cuttings have low multiplication rates and moreover diseases can be transferred through these planting materials. A technique for the micropropagation of Passiflora edulis from nodal explants has been developed at ISAR. Nodal explants are surface sterilized and inoculated in a media supplemented with $2 \%$ sucrose and $2 \mathrm{mg}$ 
$1^{-1}$ BAP (Figure 4a). Microshoots are produced (Figure $4 \mathrm{~b}$ ) and rooted in a media supplemented with an auxin (Figure $4 \mathrm{c}$ ). The rooted plantlets are then taken to the greenhouse for weaning (Figure 4d).

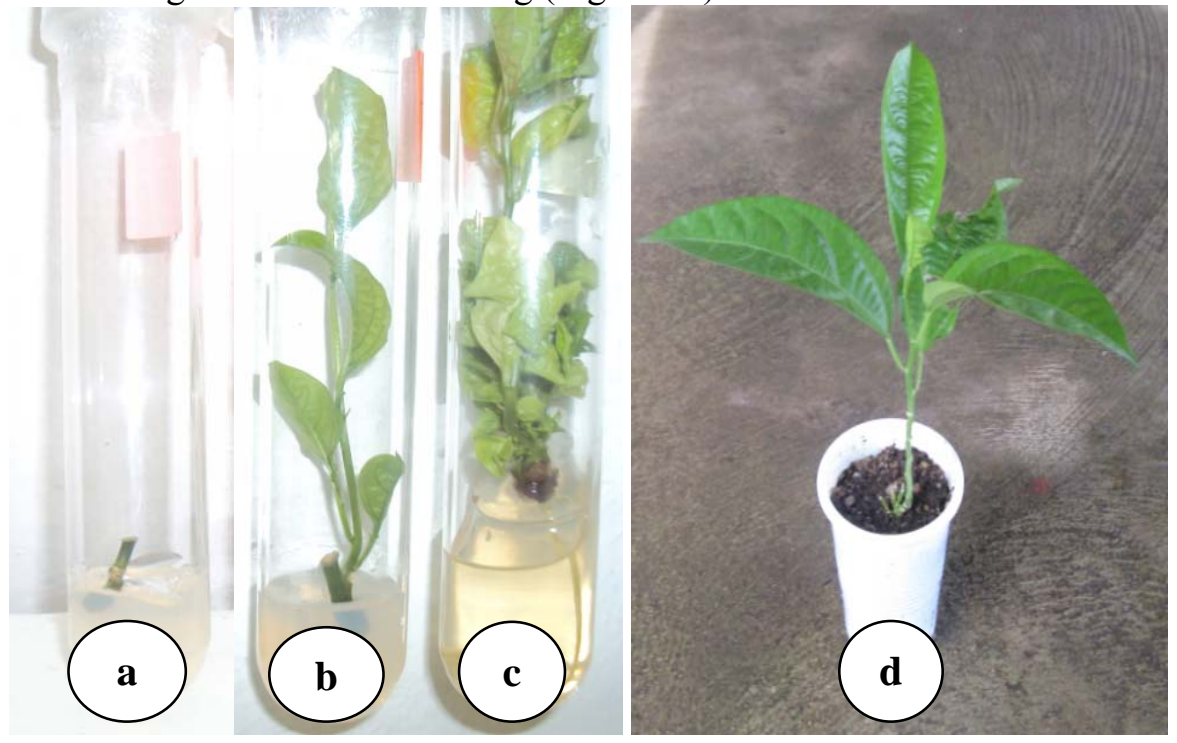

Figure 4: In vitro propagation of passion fruit

\section{Tissue culture of Tamarillo}

Cyphomandra betacea (Cav.) is commonly known as tamarillo or tree tomato. This species is mainly used for its edible fruits which have a high nutritional value and contain relatively high amounts of vitamins B6, C, E and provitamin A. The cultivation of tamarillo in Rwanda is facing major challenges caused mainly by viral diseases like tamarillo mosaic virus (TaMV). These pathogens are difficult to control and are transferred by vegetative propagation, often resulting in heavy productivity losses and poor quality fruits. The conventional methods of propagating Tamarillo are both slow and inefficient. An efficient propagation protocol has been developed at ISAR using nodal explants. Nodal explants are surface sterilized and inoculated Murashige and Skoog media supplemented with Benzyl amino purine (BAP) an incubated in a growth room maintained at $25{ }^{\circ} \mathrm{C}$ and 16 hours photoperiod (Figure 5a). Microshoot formation is observed two weeks after culturing (Figure $5 b$ ) and they reach a height of $40 \mathrm{~mm}$ in four weeks (Figure 5c) and rooting takes place without an 
exogenous source of auxin (Figure 5d). The rooted plantlets are then taken to the greenhouse for weaning (figure 5e).

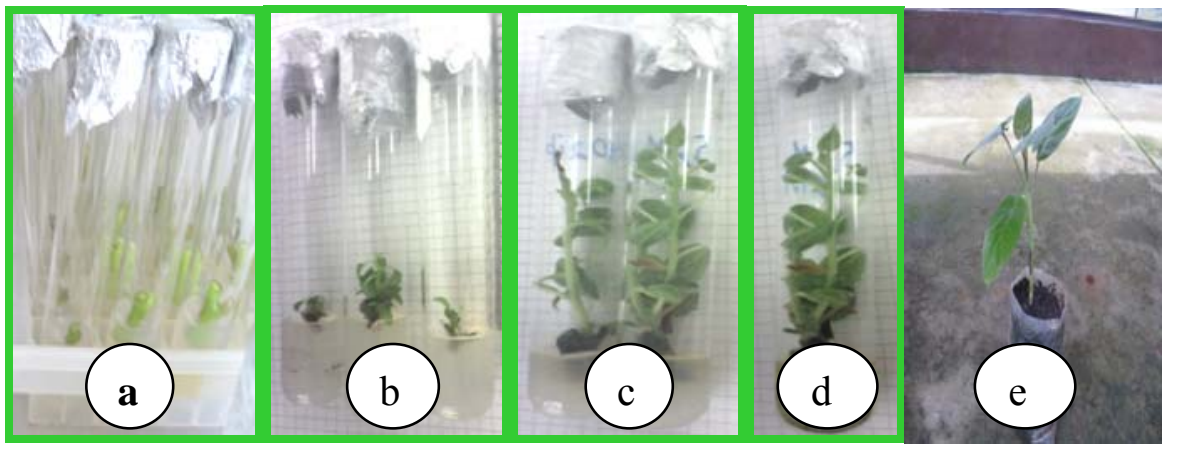

Figure 5: In vitro propagation of Tamarillo

\section{Tissue Culture of potato at Musanze}

Potato was introduced in Rwanda towards the end of the $19^{\text {th }}$ Century by missionaries from Europe. Potato farming started in Rwerere and later spread to other parts of the country. However this enterprise is faced with numerous challenges which include lack of clean seed, diseases, poor soil fertility and poor cultural practise. Clean planting are now availed to farmers using both tissue culture and aeroponics (Figure 6).
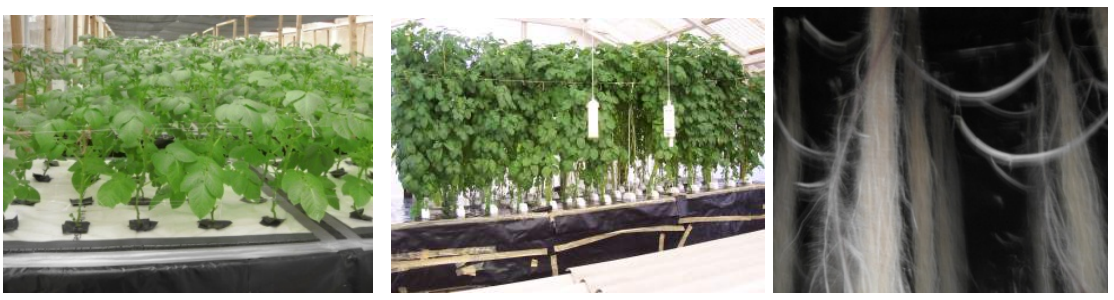

Figure 6: Aeroponic facility in Musanze

\section{Tissue culture technology in Asia}

Tissue culture has been used successfully to propagate orchid species and hybrids known to grow well in Southeast Asia. The cut flower trade has become a major source of foreign currency for Thailand, Singapore, and Malaysia and additional income for small growers (Sharma, et al., 2002).

In Thailand, tissue culture is used to reproduce slow-growing and environmentsensitive orchids. Thailand is the leader in tissue culture in Southeast Asia, 
producing 50 million plantlets a year and the country is the biggest exporter of whole and cut orchids in the world ((Vaddanaphuti, 2005).

\section{Tissue culture technology for small-scale banana producers in Kenya}

In Kenya, as in many parts of the tropical and subtropical developing world, banana is a highly important food crop. In the last 20 years, however, there was a rapid decline in banana production due to widespread soil degradation and the infestation of banana orchards with pests and diseases (Wambugu, 2001). These problems were further aggravated by the common practice of propagating banana using infected suckers. The situation was threatening food security, employment and incomes in banana-producing areas. Farmers were given tissue cultured bananas at a subsided price and with the proper cultural management the lives of thousands of poor farmers and their communities have been transformed. With proper management and field hygiene, yield losses caused by pests and diseases at farm level have been reduced substantially in Kenya (Wambugu, 2001). Tissue culture technology has made it possible for farmers to have access to the following:

- Large quantities of superior clean planting materials that are early maturing (12-16 months compared to the conventional banana of 2-3 years)

- bigger bunch weights (30-45 $\mathrm{kg}$ compared to the $10-15 \mathrm{~kg}$ from conventional material)

- higher annual yield per unit of land (40-60 tons per hectare against 15-20 tons previously realized with conventional material

Moreover, uniformity in orchard establishment and simultaneous plantation development made marketing easier to coordinate (Africa harvest, 2005)). It also offered the possibility of transforming banana growing from merely a subsistence level into a commercial enterprise.

An encouraging finding from a cost-benefit analysis of the project is that tissue culture banana production is more remunerative as an enterprise than traditional banana production (Wambugu, 2004). The project has also benefited mainly women who tend the crop, thus helping to narrow the gender gap.

\section{Conclussion}

Rwanda has made modest but significant progress in modern biotechnology applications particularly in the area of plant tissue culture. Tissue culture is one 
of the most commercially exploited components of biotechnology that has been used for the rapid clonal multiplication (micropropagtion) of selected genotypes of diverse groups of plant species (Rani and Raina, 2000). The protocols developed in Rwanda for some economically important plants/ crops can be adopted by small scale farmers and will go a long way in increasing crop productivity. It is also envisaged that this in turn will contribute to food security and poverty reduction. Tissue culture methods permit the production of relatively uniform plants on a massive scale in a shorter period than under conventional methods and this factor will contribute to the Rwandan government's efforts to replace subsistence farming by a fully commercial agricultural sector by 2020. It is also hope that the tissue culture techniques will be applied in forestry and in floriculture and in conserving rare and endangered plant species.

\section{References}

1. Africa Harvest, (2005). Annual report pg 38-42.

2. Ahloowalia B.S, Prakash J., Savangikar V.A. and Savangikar C (2002). Low cost options for tissue culture technology in developing countries Proceedings of a Technical Meeting organized by the Joint FAO/IAEA Division of Nuclear Techniques in Food and Agriculture and held in Vienna, 26-30.

3. Ahloowalia B.S., J. Prakash J., V.A. Savangikar V.A. and C. Savangikar (2004). Low cost options for tissue culture technology in developing countries. Printed by the IAEA in Austria.

4. Barciszewski J, Massino F., Clark B.F.C (2007). Kinetin-A multiactive molecule International Journal of Biological Macromolecules 40 182-192.

5. Bertrand B., Etienne H., Cilas C., Charrrier A. and Baradat P. (2005). Coffea arabica hybrid performance for yield, fertilization and bean weight. Euphytica. 141:255-262.

6. Christianson, M.L. (1987). Causal events in morphogenesis. P.45-56. In C.E. Green, D.A. Sommers, W. P. Hacket and D.D. Biesboer (eds). Plant tissue culture. Allan R. Liss. New York.

7. Hartmann HT, Kester DE, Davies FJ Jr, Geneve RL (1997) Plant propagation: principles and practices, 6th edn. Prentice Hall International (UK) Limited, London

8. Kahia W. J. (1999). In vitro propagation of the new Coffea arabica cultivar- Ruiru 11. PhD thesis. University of London. 
9. MINAGRI (Ministry of Agriculture and Animal Resources) (2004). Strategic Plan for Agricultural Transformation in Rwanda-Phase I, PSTA I.

10. Mineo, L. (1990), 'Plant tissue culture techniques', in Tested studies for laboratory Teaching Proceedings of the Eleventh Workshop/Conference of the Association for Biology Laboratory Education (ABLE), vol. 11, pp. 151-174.

11. Rani, V. and Raina, S. N. (2000). Genetic Fidelity of Organized MeristemDerived micropropagated Plants: A Critical Reappraisal. In Vitro Cell. \& Dev. Biol.-Plant, 36(5) 319-330.

12. Sharma, Jyotsna; Van Sambeek, J. W.; Starbuck, Christopher J. (2002). In vitro propagation of orchids. Fore, Stephanie, ed. Proceedings, $18^{\text {th }}$ North American Pairie Conference: Promoting Prarie; Kirksville, MO. [Saline, MI: McNaughton \& Gunn, Inc.]: 189-193.

13. United Nations, (2007). World urbanization prospects report.

14. Vaddanaphuti Nantiya, (2005). A field guide to orchids in Thailand. Published by southport. UK

15. Vibha D (1993).Tissue Culture Pilot Scale Facilities for the Mass

16. Cloning of Forest Tree Species Tata Energy Research Institute 90, JorBagh New Delhi - 110003.

17. Wambugu Florence, (2001). Modifying Africa: How Biotechnology can benefit the poor and hungry.- A case study from Kenya. Amazon publishers, UK.

18. Wambugu Florence, (2004). Modifying Africa: How Biotechnology can benefit the poor and hungry. Amazon publishers, UK

19. Ziv, M. (1999). Developmental and structural patterns of in vitro plants In: W.Y.Soh and S.S. Bohjwani (eds). Morphogenesis of plants in tissue culture. Kluwer Acad. Publ. Dordrecht. The Netherlands. 
'Rwanda Journal' publishes the following four series:

Series A: Arts and Humanities

1. Fine and performing arts

2. Mass communication \&Media studies

3. Language and Linguistics

4.Information Studies (Library, archives, ...)

5. History

6. Religion

7. Psychology

etc

Series C: Mathematical Sciences Engineering and Technology

1. Mathematics

2. Statistics

3. Computer Science

4. All branches of Engineering

5. Applied Physics

6. Technology, ICT, Geographic information Sciences (GIS)

7. Theoretical Physics

8. Electronic Sciences

9. Biotechnology, Bioinformatics, Biometrics, Biostatistics, etc

\section{Series E: Agricultural Sciences}

1. Agriculture

2. Environment

3. Veterinary Medicine

\section{Series B: Social Sciences}

1. Political Sciences

2. Sociology, Social Work

3. Education Human resources, Administration

5. Management \& Business studies

6. Economics

7. Gender Studies

8. Peace and Conflict Studies

9. Psychology etc

Series D: Life Sciences and Natural Sciences

1. Biological Sciences

2. Chemistry

3. Physical Sciences

4. Geography

5. Earth Sciences, Forestry, GIS

6. Biotechnology, Bioinformatics, Biometrics, Biostatistics, etc

\section{Series G: Law}

1. Law

2. Justice

3. Human rights and related fields

\section{Series F: Health Sciences}

1. Medicine

2. Pharmacy

3. Mental Health

4. Public Health

\section{Series H: Economics and}

Management

1. Economics

2. Management and related fields

Authors have the right to specify in which series they think their articles fit best. 